\section{PEDIATRIC ANESTHESIOLOGY FELLOWSHIP}

\author{
The department of Anesthesiology at \\ The Children's Hospltal of Buffalo \\ is offering one year fellowships in Pediatric \\ Anesthesiology starting July 1999. \\ The position includes basic seience and \\ clinical research opportunities. \\ The fellowship has dedicated time for \\ ICN, ICU, and Cardiology rotatious \\ Please send inquires to \\ Dorod Feldman, MD \\ Pediatric Anesthesia Fellowship \\ Program Director \\ Children's Hospltal of Buffalo \\ 219 Bryant Street \\ Buffalo, NY 14222 \\ USA \\ (716) 878-7701 \\ Fax (716) 878-7316 \\ e-mail: dfeldman@acsu.buffalo.edu
}

\section{DISTANCE EDUCATION}

\section{Anaesthesia Technology Program}

\section{For Registered Respiratory} Therapists \& RNs

This UCC Program consists of a didactic portion and a clinical practicum. The didactic portion of the program is offered on a tutor-supported distance study format with continuous enrollment. For more information, please contact

David Sheets Program Coordinator Email: Dsheets@caribpo.bc.ce Telephone: $250 / 828-5465$ Fax: 250/371-5771 Visit our website at: www.cariboo.bc.ca/ schs/home.htm

Kamloops, British Columbia

\title{
FACULTY POSITIONS AT ALL RANKS
}

The University of Iowa Department of Anesthesia is actively recruiting candidates for faculty positions. The Department of Anesthesia is committed to the appointment and support of highly promising individuals who will bring special interests and expertise in: 1) critical care medicine, 2) cardiothoracic anesthesia, 3) regional anesthesia, 4) pain medicine, 5) neuroanesthesia and 6) research.

The Department seeks inquiries from anesthesiologists interested in working in a collegial setting where research, clinical care and education are all valued. The University of Iowa is located in Iowa City, a vibrant community located in the rolling hills of southeastern lowa. The community offers excellent schools, quality entertainment, literary, musical and cultural opportunities and Big-10 sporting events. Please send CV and contact:

David L. Brown, M.D., Professor and Head Department of Anesthesia, The University of Iowa

200 Hawkins Drive, Room 6618 JCP

Iowa City, Iowa 52242-1079

Telephone (319) 356-2382 or Fax (319) 356-4130

Web; http://www.anesth.uiowa.edu

E-mail: anesthesia@uiowa.edu

The University of Iowa is an Affirmative Action and Equal Opportunity Employer. Women and minorities are strongly encouraged to apply. 